\title{
Vasectomy: tips and tricks
}

\author{
Dane Johnson, Jay I. Sandlow \\ Department of Urology, Medical College of Wisconsin, Milwaukee, WI, USA \\ Contributions: (I) Conception and design: All authors; (II) Administrative support: All authors; (III) Provision of study material or patients: All authors; \\ (IV) Collection and assembly of data: All authors; (V) Data analysis and interpretation: All authors; (VI) Manuscript writing: All authors; (VII) Final \\ approval of manuscript: All authors. \\ Correspondence to: Jay I. Sandlow. Department of Urology, Medical College of Wisconsin, Milwaukee, WI, USA. Email: jsandlow@mcw.edu.
}

\begin{abstract}
According to data from the National Study of Family Growth, vasectomy is utilized by 6-13\% of American couples for their form of contraception. Physician surveys have shown that over 500,000 men undergo vasectomies per year, and more than $75 \%$ of vasectomies are performed by urologists. This chapter provides a brief history of vasectomy, as well as recommendations for preoperative counseling, an overview of the modified no-scalpel vasectomy technique, and a brief description of the complications of vasectomy.
\end{abstract}

Keywords: Vasectomy; no-scalpel; post-vasectomy pain; post-vasectomy semen analysis (PVSA)

Submitted Apr 15, 2017. Accepted for publication June 29, 2017.

doi: $10.21037 /$ tau.2017.07.08

View this article at: http://dx.doi.org/10.21037/tau.2017.07.08

\section{Introduction}

According to data from the National Study of Family Growth, vasectomy is utilized by $6-13 \%$ of American couples for their form of contraception $(1,2)$. Physician surveys have shown that over 500,000 men undergo vasectomies per year (3), and more than $75 \%$ of vasectomies are performed by urologists (4). This chapter provides a brief history of vasectomy, as well as recommendations for preoperative counseling, an overview of the modified noscalpel vasectomy technique, and a brief description of the complications of vasectomy.

\section{Historical perspective}

Sir Ashley Cooper first described vasectomy in 1827 as a sterilization procedure first performed on canines in the United Kingdom (5). However, vasectomies did not enter clinical use until the late $19^{\text {th }}$ century, at which time vasectomies were felt to induce prostatic atrophy, and were widely performed as an alternative to castration to reduce symptoms of prostatic hypertrophy and improve micturition (6). This eventually fell out of favor by the early $20^{\text {th }}$ century as evidence accumulated that vasectomy had no such benefit for patients with symptoms of enlarged prostates.

Around this same time, many promoted vasectomy for eugenic sterilization (7). Ochsner, Surgeon-in-Chief of Augustana Hospital and St Mary's Hospital in Chicago, and eventual president of American College of Surgeons, suggested vasectomy specifically for habitual criminals and "chronic inebriates, imbeciles, perverts and paupers" to protect the community without harming the recipients (8). This remained a popular means of eugenic sterilization during the first half of the $20^{\text {th }}$ century. As the popularity for eugenics declined mid-century, the practice of involuntary sterilization gradually declined, and has been prohibited since the 1960s.

Voluntary sterilization by vasectomy surprisingly took much longer to gain widespread popularity. Up until 1969, the American College of Obstetricians and Gynecologists recommended restricting voluntary sterilization to men or women whose age multiplied by number of children equaled or exceeded 120 (9). Between 1963 and 1967, only 40,000 vasectomies were performed annually in the United States (10). As opinion on self-sterilization improved, vasectomy became increasingly popular, and by 1991, the number of vasectomies performed annually in the US increased to 493,487 (11). However, even today vasectomy is underutilized. In the United States, nearly 3 times as 
many couples choose to have tubal ligation compared to vasectomy (12) as their form of contraception, despite the increased risk and higher cost associated with female sterilization.

\section{Preoperative counseling}

Preoperative consultation is important with any surgical procedure to ensure patients are fully prepared for the potential risks, benefits and alternatives prior to committing to a procedure. For this reason, AUA guidelines recommend preoperative consultation should always be performed, and preferably performed in person (13).

During consultation the patient should be counseled that vasectomy is not immediately effective for sterility, and another form of birth control should be used until "successful vas occlusion is confirmed by post-vasectomy semen analysis (PVSA)". The time from vasectomy to azoospermia or rare non-motile sperm (RNMS) can vary from weeks to months, depending on frequency of ejaculation, patient age and anatomical variation (13). RNMS is defined as $<100,000$ non-motile sperm $/ \mathrm{mL}$ in a fresh semen sample. Post-vasectomy semen analyses are necessary to demonstrate success of the procedure. Patients who fail to achieve azoospermia or RNMS may require repeat vasectomy.

Once a PVSA has been obtained and demonstrates sterility (azoospermia or RNMS), the risk of pregnancy is 1 in 2,000. If a provider follows the techniques as described below, repeat vasectomy is rarely needed, with rates of $<1 \%$. Lastly, an important point to highlight is that vasectomy should be considered a permanent form of contraception, and although options for fertility after vasectomy are possible (vasectomy reversal or sperm retrieval with in vitro fertilization), these are expensive and not $100 \%$ successful. According to a study examining patient expectations and concerns, only $15 \%$ of men seeking vasectomy indicated they understood that a vasectomy was not a reversible form of birth control, while $30 \%$ believed vasectomy to be reversible. A little over half of the men (55\%) were not certain (14). Most vasectomies can be performed in the clinician's office, utilizing local anesthesia. However, in a subset of patients with either elevated anxiety or anatomy making mobilization of vas difficult or painful, moderate sedation can be utilized. In our practice, when moderate sedation is required we only perform vasectomies with anesthesiology monitoring. Therefore, preoperative consultation should involve an examination of the scrotal contents, including mobilization of vas, to identify whether a patient may require sedation during vasectomy.

\section{Vas isolation}

Once pre-operative consultation has been completed and patient arrives for vasectomy, low dose anxiolytic can be provided to patient (if requested by patient), after which he is placed in a supine position and skin prepped using sterile technique, and draped. Several methods of mobilizing and isolating the vas have been described, including the no scalpel technique (as first developed by Li et al.), as well as the conventional vasectomy approach. The original noscalpel technique involves applying a vas ring clamp directly around the vas, peri-vasal tissue and overlying skin (after local anesthesia is administered). The skin is then pierced with the vas dissector or sharp tipped hemostat, spreading overlying tissue to expose the anterior wall of vas (13). A conventional vasectomy utilizing scalpel incisions has fallen out of favor with many urologists, as comparative studies have shown the no-scalpel approach to result in less bleeding, hematoma, infection and pain compared to the conventional incision technique (15). As utilized in our practice, we will review the steps of the modified no-scalpel technique, which has also been referred to as the minimallyinvasive vasectomy.

With patient in comfortable supine position, the vas is grasped between index finger and thumb. The skin and vas are then mobilized to the lateral or anterior position of the scrotum, or for those who wish to utilize just one puncture site, near the penoscrotal junction, ensuring the straight segment of the vas is isolated. Local anesthetic is injected into subcutaneous and peri-vasal tissues using either traditional intradermal needle (27 or $30 \mathrm{G}$ ) or noneedle jet injector. The vas dissector is then used to pierce the anesthetized skin. The skin and underlying tissue are then spread, widening the puncture to $\sim 10 \mathrm{~mm}$. Utilizing the vas ring clamp, the vas is grasped and delivered through the wound. The vas dissector is then one again used to pierce directly into the lumen of the vas, and the overlying peri-vasal fascia is spread to expose the anterior wall of the vas. The ring clamp is then adjusted to encompass only vas, and the peri-vasal fascia and vascular bundle swept away from posterior wall with a raytec sponge. Local anesthesia is then injected into the peri-vasal tissue proximally and distally (useful to provide additional anesthetic for the electrocautery), and a small hemostat is placed on the perivasal fascia to anchor the vas above the wound. 


\section{Vas occlusion}

In the US, virtually all techniques of vasectomy use complete division of the vas with or without excision of the vas (3). However, once divided, there are multiple additional measures that can be taken to ensure permanent occlusion of the vas. The most commonly used occlusion techniques involve excision of vas, cauterization of mucosal surface of the vas lumen, followed by fascial interposition. The effectiveness of each technique has been thoroughly evaluated, and results from these studies have been compared in attempts to identify the optimal approach to occlusion. Based on this body of literature, the AUA Guidelines recommend the ends of the vas be occluded by one of three methods; mucosal cautery with fascial interposition, mucosal cautery alone, or open ended vasectomy with fascial interposition leaving the testicular end of vas un-occluded while using cautery on the abdominal end (16). Using one of these three methods reduces the risk of technical failure to $<1 \%$. Other techniques not described previously have been found to have wide range of vasectomy failure rates, some as high as $13.7 \%$, and should not be performed except by experienced practitioners whose personal experience enable them to consistently obtain low failure rates. Based on these findings and recommendations, we have adopted excision, mucosal cautery and fascial interposition into our practice.

Once the vas is mobilized and anchored in place with the hemostat attached to peri-vasal tissue, the vas is divided utilizing electrocautery. The insulated needle-tip Bovie cautery device is then inserted $\sim 8-10 \mathrm{~mm}$ into the lumen of the vas, and the mucosa is cauterized until lumen appears opaque and white, taking care not to fully destroy the entire vasal wall, which could lead to necrosis and subsequent sloughing of the vasal end. Transection and excision of $\sim 1 \mathrm{~cm}$ segment of vas is then completed. Fascial interposition is then performed by grasping peri-vasal fascia and placing a small hemoclip over the tissue, thus burying the abdominal end of vas, and effectively separating the two ligated ends. Once hemostasis is ensured, the vasal ends are returned to the hemiscrotum.

\section{Completion of procedure and postoperative care}

The vasectomy puncture site is then closed by grasping dartos underneath skin, and cauterizing with Bovie, effectively welding shut the puncture deep to the skin. Skin is left to close secondarily. The identical procedure is performed on the contralateral side through a new puncture site, although some providers prefer one midline opening. A clear watertight dressing or bandages can be applied prior to placement of scrotal support.

Postoperative care is similar to other scrotal surgery, and include limiting physical activity and utilizing non-steroidal anti-inflammatory drugs, as well as mild narcotics (if necessary) for pain management. Every patient is provided an athletic supporter at time of his vasectomy. We have found that the incidence of prolonged testicular discomfort is greatly reduced by having the patient wear this for 1-2 weeks. Additionally, men are encouraged to use ice on scrotum intermittently for 24-48 hours, and minimize physical activity for 1 week. We do not require patients to return for postoperative wound evaluation, unless patient is experiencing unexpected pain or other concerns.

\section{Post vasectomy follow up}

A PVSA is obtained at $8-12$ weeks after the vasectomy to confirm technical success. Most men will achieve azoospermia during this interval. However, a small portion will continue to have non-motile sperm in the ejaculate post vasectomy. According to one study, up to $33 \%$ of samples will be non-azoospermic at 12 weeks (17). Because of this, several studies have evaluated men with RNMS in the PVSA. These studies, having followed the men prospectively for several years, have reported zero pregnancies despite persistence of non-motile sperm in the ejaculate $(18,19)$. Furthermore, the pregnancy rate is not significantly different from the 1 in 2,000 risk after azoospermia based on several large case series reports $(20,21)$. This data has been used by both the AUA and British Andrology Society guidelines when labeling RNMS $(<100,000 / \mathrm{mL})$ as effective for contraception $(13,22)$, at which point patients may stop using other methods of contraception.

When $>100,000$ non motile sperm/mL, or motile sperm are found on the initial 3-month PVSA, men should be counseled to continue another form of contraceptive, and repeat another semen analysis in 2-3 months. Clinical judgement should be used to determine when repeat vasectomy should be offered for these patients; however, most studies show that if motile sperm are still present at 6 months post vasectomy, early recanalization has occurred and the vasectomy should be repeated. The presence of motile sperm at the time of the first PVSA, however, may not represent early recanalization and not all of these men 
require repeat vasectomy. Several studies evaluating men with motile sperm on PVSA have reported the complete disappearance of spermatozoa over subsequent semen analyses $(23,24)$. According to one series following 309 men with motile sperm on first post vasectomy semen analysis, $56.3 \%$ experienced complete disappearance of spermatozoa on subsequent semen analysis, with mean number of semen analysis $2.4 \pm 0.8$ (25). However, if motile sperm are identified on semen analysis 6 months after vasectomy, these men should be offered repeat vasectomy for persistent recanalization. As described previously, vasectomies performed utilizing mucosal cauterization and fascial interposition are associated with a $<1 \%$ risk for vasectomy failure requiring repeat vasectomy.

\section{Complications}

The rates of surgical complications such as symptomatic hematoma and infection are rare, associated with 1-2\% of minimally invasive vasectomies (13). As described previously, the minimally invasive or no-scalpel techniques are associated with decreased risk for both hematoma and infections (3). Short term scrotal discomfort lasting 2-4 weeks can occur in as many as $30 \%$ of men undergoing vasectomy (26). Fortunately, the majority of patients with acute pain and swelling after vasectomy can be managed conservatively and pain typically resolves without further intervention.

Chronic scrotal pain after vasectomy is possibly the most troublesome and vexing complication of vasectomy. Chronic pain has no association with immediate postoperative complications such as infection, or hematoma (27). Chronic scrotal pain, also known as post vasectomy pain syndrome, can persist for months to years, and is defined as constant or intermittent testicular pain for 3 months or longer with a severity that interferes with daily activities prompting the patient to seek medical attention (28). The pathophysiology leading to post vasectomy pain is unclear, and felt to be potentially related to inflammation resulting in damage and fibrosis of spermatic cord nerves (29). While 1-2\% of patients after vasectomy experience this complication, conservative management with NSAIDS and scrotal support help avoid need for more invasive interventions. The majority of men with post vasectomy scrotal pain can be managed conservatively (30).

However, men with pain refractory to conservative measures may potentially benefit from surgical intervention. When pain is localized to the site of a sperm granuloma, excision of the granuloma can relieve pain and prevent recurrence (31). Men who experience pain with ejaculation can be offered vasectomy reversal, with upwards of $84 \%$ experiencing improvement after vasovasostomy (32). Conversely, if these patients desire to maintain surgical sterility, epididymectomy can be performed with good results (33). In patients with chronic pain not clearly confined to epididymis or granuloma, microsurgical spermatic cord denervation can be considered. These men, who previously experienced temporary pain relief from a spermatic cord block and subsequently undergo microsurgical cord denervation, experience complete pain relief in $76 \%$ of cases, and significant improvement in an additional 9\% (34). Men who experience continued pain despite surgical measures may be best managed with referral to pain clinic for additional pain management instruction. Lastly, in men with chronic pain who fail to respond to surgical and medical intervention, inguinal orchiectomy may be required. Unfortunately, pain relief is not guaranteed, with $27 \%$ reported to have continued pain post-orchiectomy (35), and should only be considered as a last resort for refractory post vasectomy pain. It is the authors' experience that much of the chronic pain is due to inflammation. Therefore, we have found it useful to have patients wear scrotal support or compression shorts for 1-2 weeks following the procedure in order to minimize pulling of the spermatic cord. This appears to have lessened the number of calls and postoperative visits. We have also stressed the need for no heavy lifting for the first 5-7 days in order to reduce the likelihood of scrotal hematoma. While this still occurs infrequently, most are small hematomas secondary to the administration of local anesthesia (rather than capillary oozing), and can be managed conservatively.

\section{Key points}

(I) A preoperative consultation should be conducted prior to vasectomy, and examination performed at that time to identify patients who may require sedation or have other abnormalities that need to be addressed;

(II) Isolation of the vas should be performed using a minimally invasive vasectomy technique;

(III) The ends of the divided vas should be occluded by one of three methods: mucosal cautery with fascial interposition, mucosal cautery without interposition, or fascial interposition with mucosal cautery on only the abdominal end of the vas; 
(IV) Men or their partners should use other contraceptive methods until vasectomy success is confirmed on post vasectomy semen analysis;

(V) Post vasectomy semen analysis obtained at 8-12weeks demonstrating either azoospermia or only RNMS $(<100,000 / \mathrm{mL})$ demonstrates technical success. These patients with this finding can stop using other methods of contraception;

(VI) Vasectomy should be considered a failure if any motile sperm are seen on their 6-month PVSA.

\section{Acknowledgements}

None.

\section{Footnote}

Conflicts of Interest: The authors have no conflicts of interest to declare.

\section{References}

1. Eisenberg ML, Lipshultz LI. Estimating the number of vasectomies performed annually in the United States: data from the National Survey of Family Growth. J Urol 2010;184:2068-72.

2. Anderson JE, Warner L, Jamieson DJ, et al. Contraceptive sterilization use among married men in the United States: results from the male sample of the National Survey of Family Growth. Contraception 2010;82:230-5.

3. Barone MA, Hutchinson PL, Johnson CH, et al. Vasectomy in the United States, 2002. J Urol 2006;176:232-6; discussion 236.

4. Haws JM, Morgan GT, Pollack AE, et al. Clinical aspects of vasectomies performed in the United States in 1995. Urology 1998;52:685-91.

5. Cooper A. The Anatomy and surgical Treatment of abdominal hernia. Available online: https://archive.org/ details/anatomysurgicalt 00 coop

6. Sheynkin YR. History of vasectomy. Urol Clin North Am 2009;36:285-94.

7. Kogan P, Wald M. Male contraception: history and development. Urol Clin North Am 2014;41:145-61.

8. Ochsner AJ. The surgical treatment of habitual criminals, imbeciles, perverts, paupers, morons, epileptics, and degenerates. Ann Surg 1925;82:321-5.

9. Stallworthy J, Walker K, Malleson J, et al. Problems of fertility in general practice. London: Cassell and Co.,1953.
10. Davis JE, Hulka JF. Elective vasectomy by American urologists in 1967. Fertil Steril 1970;21:615-21.

11. Magnani RJ, Haws JM, Morgan GT, et al. Vasectomy in the United States, 1991 and 1995. Am J Public Health 1999;89:92-4.

12. Chandra A, Martinez GM, Mosher WD, et al. Fertility, family planning, and reproductive health of U.S. women: data from the 2002 National Survey of Family Growth. Vital Health Stat 2005;(25):1-160.

13. Li SQ, Goldstein M, Zhu J, et al. The no-scalpel vasectomy. J Urol 1991;145:341-4.

14. Sandlow JI, Westefeld JS, Maples MR, et al. Psychological correlates of vasectomy. Fertil Steril 2001;75:544-8.

15. Cook LA, Pun A, Gallo MF, et al. Scalpel versus no-scalpel incision for vasectomy. Cochrane Database Syst Rev 2014;(3):CD004112.

16. Sharlip ID, Belker AM, Honig S, et al. Vasectomy: AUA guideline. J Urol 2012;188:2482-91.

17. Smith AG, Crooks J, Singh NP, et al. Is the timing of post-vasectomy seminal analysis important? Br J Urol 1998;81:458-60.

18. Rajmil O, Fernández M, Rojas-Cruz C, et al. [Azoospermia should not be given as the result of vasectomy]. Arch Esp Urol 2007;60:55-8.

19. Lemack GE, Goldstein M. Presence of sperm in the pre-vasectomy reversal semen analysis: incidence and implications. J Urol 1996;155:167-9.

20. Davies AH, Sharp RJ, Cranston D, et al. The long-term outcome following "special clearance" after vasectomy. $\mathrm{Br}$ J Urol 1990;66:211-2.

21. Alderman PM. The lurking sperm. A review of failures in 8879 vasectomies performed by one physician. JAMA 1988;259:3142-4.

22. Hancock P, McLaughlin E; British Andrology Society. British Andrology Society guidelines for the assessment of post vasectomy semen samples (2002). J Clin Pathol 2002;55:812-6.

23. Alderman PM. General and anomalous sperm disappearance characteristics found in a large vasectomy series. Fertil Steril 1989;51:859-62.

24. Eldrup J. Transient spontaneous recanalization after vasectomy. Ugeskr Laeger 1979;141:383.

25. Labrecque M, St-Hilaire K, Turcot L. Delayed vasectomy success in men with a first postvasectomy semen analysis showing motile sperm. Fertil Steril 2005;83:1435-41.

26. Celigoj FA, Costabile RA. Surgery of the scrotum and seminal vesicles. In: Wein AJ, Kavoussi LR, Partin AW, 
et al. editors. Campbell-Walsh Urology. 11th edition. Philadelphia, PA: Elsevier Saunders, 2016:41.

27. Leslie TA, Illing RO, Cranston DW, et al. The incidence of chronic scrotal pain after vasectomy: a prospective audit. BJU Int 2007;100:1330-3.

28. Granitsiotis P, Kirk D. Chronic testicular pain: an overview. Eur Urol 2004;45:430-6.

29. McMahon AJ, Buckley J, Taylor A, et al. Chronic testicular pain following vasectomy. Br J Urol 1992;69:188-91.

30. Tandon S, Sabanegh E Jr. Chronic pain after vasectomy: a diagnostic and treatment dilemma. BJU Int 2008;102:166-9.

31. Schmidt SS. Spermatic grauloma: an often painful lesion.

Cite this article as: Johnson D, Sandlow JI. Vasectomy: tips and tricks. Transl Androl Urol 2017;6(4):704-709. doi: 10.21037/tau.2017.07.08
Fertil Steril 1979;31:178-81.

32. Myers SA, Mershon CE, Fuchs EF. Vasectomy reversal for treatment of the post-vasectomy pain syndrome. J Urol 1997;157:518-20.

33. Siu W, Ohl DA, Schuster TG. Long-term follow-up after epididymectomy for chronic epididymal pain. Urology 2007;70:333-5; discussion 335-6.

34. Levine LA, Matkov TG. Microsurgical denervation of the spermatic cord as primary surgical treatment of chronic orchialgia. J Urol 2001;165:1927-9.

35. Davis BE, Noble MJ, Weigel JW, et al. Analysis and management of chronic testicular pain. J Urol 1990;143:936-9. 